\title{
Intravenous immunoglobulin therapy in multiple sclerosis: progress from remyelination in the Theiler's virus model to a randomised, double- blind, placebo-controlled clinical trial
}

\author{
John H Noseworthy, Peter C O’Brien, Baziel G M van Engelen, Moses Rodriguez
}

\begin{abstract}
No treatment has been found which reverses long-standing neurological dysfunction in patients with multiple sclerosis (MS). Observations in animal models of MS show that immunoglobulins directed against CNS components promote oligodendroglial proliferation and new myelin synthesis. Preliminary studies in inflammatory-demyelinating diseases of the human peripheral and central nervous system suggest that the repeated intravenous administration of polyclonal human immunoglobulin (IVIg) is sometimes followed by clinical improvement. A randomised, placebo-controlled, doubleblind, clinical trial was designed to test the hypothesis that repeated administration of IVIg will result in a meaningful degree of recovery of apparently irreversibly lost neurological function (weakness). A total of 76 patients with MS will participate in the study. These patients had developed a fixed, apparently permanent weakness that had not improved in the preceding four to 18 months. If effective, IVIg administration may benefit the large proportion of patients with MS who have active disease by enhancing the potential for myelin repair in the evolution of the inflammatory-demyelinating lesion.
\end{abstract}

CNS remyelination by oligodendrocytes ${ }^{1-5}$ and Schwann cells ${ }^{67}$ occurs in multiple sclerosis (MS) lesions. It is not known why remyelination and clinical recovery is incomplete. Whereas oligodendrocyte proliferation and remyelination is minimal in the centre of chronic MS plaques, at the edge of demyelinated plaques, remyelination by oligodendrocytes occurs as documented by abnormally thin myelin sheaths relative to axon diameter. ${ }^{3}$ These findings suggest the potential for promotion of myelin repair in the evolution of the inflammatory-demyelinating lesion in MS.

Much of our experimental work has been focused on efforts to encourage remyelination in experimental animal models of MS. This work has led initially to a pilot clinical trial of intravenous immunoglobulin (IVIg) in MS patients and, thereafter, to a randomised, double-blind, placebo-controlled clinical trial.

\section{Experimental studies}

We have used a model induced by Theiler's murine encephalomyelitis virus (TMEV) to study the mechanisms of demyelination and remyelination in the CNS. ${ }^{8}$ Following intracerebral injection of Daniel's (DA) strain of TMEV into SJL mice, there is extensive immune-mediated demyelination with relative absence of remyelination in the spinal cord. ${ }^{8}$ The demyelination seen following chronic TMEV infection is indistinguishable pathologically from MS. ${ }^{910}$ Recurrent episodes of demyelination are superimposed on the chronic progressive disease. ${ }^{11}$ Histologically there is primary demyelination (destruction of myelin sheaths with axon preservation), and lymphocytes, plasma cells and macrophages are intimately involved in the demyelinating lesion.

The precise mechanisms by which TMEV induces demyelination is unknown. Because TMEV injures oligodendrocytes, cytopathological injury to oligodendrocytes may result in demyelination. ${ }^{1213}$ The observation that nude mice develop demyelination following TMEV infection indicates that $T$-cells are not required for the initiation of demyelination. ${ }^{14}$ In addition, there is considerable evidence implicating an immune-mediated mechanism underlying TMEV-induced demyelination. The inflammatory infiltrate is closely associated morphologically with areas of demyelination. ${ }^{10}$ Immunosuppression with cyclophosphamide, anti-lymphocyte serum, cyclosporine and monoclonal antibodies (mAbs) to class II MHC products reduces the extent of demyelination. ${ }^{15-18}$ Both class Irestricted and class II-restricted T-cells appear to be important in the late phases of TMEV-induced demyelination. In vivo therapy with mAbs directed against class Irestricted $\mathrm{CD}^{+} \mathrm{T}$-cells or class II-restricted $\mathrm{CD4}^{+} \mathrm{T}$-cells suppresses the extent of demyelination. ${ }^{19} 20$

Administration of emulsions of myelin basic protein plus galactocerebroside and incomplete Freund's adjuvant may enhance remyelination in the chronic guinea pig EAE model. ${ }^{21-23}$ We therefore considered the possibility that differences in remyelination in the TMEV model may be determined by the immune response. Immunisation with serum directed against spinal cord homogenate 
(anti-SCH serum) induced extensive remyelination in SJL mice chronically infected with TMEV. ${ }^{24}$ To determine whether the humoral immune response was important in controlling remyelination, mice chronically infected with TMEV were treated for up to nine months with intraperitoneal injections of antiSCH serum. CNS remyelination was extensive in TMEV-infected SJL mice treated with anti-SCH sera compared with sera from control groups of mice. ${ }^{25}$

Our recent studies have shown that IgG contained in the anti-SCH serum was responsible for this effect. ${ }^{26} 27$ In addition to IgG directed against $\mathrm{SCH}$, commercially prepared, polyclonal mouse IgG also promotes extensive remyelination in SJL mice chronically infected with Theiler's virus. Remyelination was not seen with an IgG1 monoclonal antibody (MOPC 21) or in borate buffered saline-treated control animals. The polyclonal mouse IgG used in these experiments was commercially prepared from nonsyngeneic donor mice and is analogous to the human IgG preparation proposed in our clinical trial.

Conventional wisdom has assumed that IgG plays a role in the putative immunemediated injury in MS. However, the specificity of the IgG molecules in the cerebrospinal fluid and in the MS lesion remains undetermined. The concept that IgG may promote remyelination is novel and has received little attention.

\section{Clinical studies}

We have recently reported the ultrastructural features of $11 \mathrm{MS}$ stereotactic brain biopsies with clinical and radiological correlation. ${ }^{28}$ Oligodendrocytes were morphologically preserved in early lesions and appeared to increase in number at the edge of plaques in areas of remyelination. Our results agree with those of Prineas et al who has shown extensive oligodendrocyte regeneration and remyelination in acute and subacute MS lesions. ${ }^{134}$ The oligodendrocytes responsible for this remyelination appear to be previously undifferentiated, immature oligodendrocytes rather than, surviving, previously differentiated mature myelin-producing oligodendrocytes.

There is preliminary evidence that IVIg may reverse neurological dysfunction in patients with long standing optic neuritis. ${ }^{29} \mathrm{~A}$ recently completed study ${ }^{30}$ suggests that IVIg administration may be followed by improved neurological function in patients with chronic, steroid-unresponsive optic neuritis. Improvement was temporally related to the administration of IVIg and persisted for the follow up period of $1 \cdot 2-1 \cdot 7$ years. These findings suggest that exogenously administered human IgG promotes remyelination in patients with MS with nonresolving optic neuritis.

Possible mechanisms of action of IVIg The mechanisms of action of IVIg in the few diseases for which it has proven efficacy are only partially understood. These include saturation of Fc receptors on reticuloendothelial cells (acute autoimmune thrombocytopenic purpura of childhood ${ }^{31-32}$ ) and $B$ and $T$ cells resulting in modulation of the immune response, ${ }^{33-34}$ reduced natural killer cell activity (autoimmune idiopathic thrombocytopenic purpura and autoimmune neutropenia ${ }^{35}$ ), and neutralisation of putative autoantibodies by naturally occurring antiidiotypic antibodies within the IVIg preparation. ${ }^{36} 37$

The mechanism by which polyclonal IgG promotes remyelination and glial cell proliferation in the Theiler's virus model is unknown. As discussed above, it is proposed that there may be antibodies within the anti-SCH serum that stimulate progenitor glial cell proliferation following binding to a cell surface receptor responsible for growth or differentiation. These mechanisms are known to occur in other examples of autoimmunity..$^{38-42}$

\section{Mayo clinic randomised trial of IVIg therapy in multiple sclerosis}

We are currently completing an open-label, pilot study of IVIg in 10 patients with MS using a protocol identical to the proposed fullscale clinical trial (with the exception of the placebo-controlled limb). This pilot study has allowed us to assess the safety of IVIg in this subset of patients with MS, to assess the adequacy of our proposed adverse effects surveillance mechanisms, and to gain experience with the treatment and outcome measurement methods to be used in the controlled trial.

The overall goal of this randomised, double-blind and placebo-controlled clinical trial is to determine whether IVIg administration is followed by clinical improvement of apparently irreversibly lost motor function (muscle strength) in patients with MS. This trial differs from other prospective MS clinical trials because we are attempting to assess whether experimental treatment results in clinical improvement rather than delay or prevention of further progression.

Inclusion criteria: Patients must have clinically definite ${ }^{43}$ or laboratory supported definite $\mathrm{MS}^{44}$ which has been either relapsing-remitting or relapsing-progressive (secondary progressive) from onset. Patients must be between the ages of 18 and 60 and have a fixed, apparently irreversible, motor deficit ("targeted neurological deficit"): weakness of at least one limb which has been documented in the Department of Neurology at the Mayo Clinic to have been present and static for four and 18 months).

Patients must not have received ACTH, immunosuppressive therapy, corticosteroids, or plasma exchange within the preceding three months. The observed duration of the fixed neurological motor deficit was chosen to minimise the likelihood of delayed, spontaneous, unexpected and possibly placeborelated recovery of the 'targeted neurological deficit'. ${ }^{45}$ 
Exclusion criteria: This includes primary progressive MS, pregnancy, ${ }^{4647}$ ischaemic heart disease, cerebrovascular disease, dementia, antibody deficiency states, sensitivity to IVIg and albumin, and medical illnesses requiring IVIg administration.

Protocol schedule: In this trial, 76 patients will be randomised to receive either IVIg (Gamimune N, Miles Pharmaceuticals; 5\% solution in $10 \%$ maltose) or placebo $(0.1 \%$ human serum albumin in $10 \%$ maltose) daily for five days and thereafter every two weeks for three months (total: 11 infusions). All patients will be re-examined at three and six months. In our efforts to determine whether long-standing motor dysfunction can be reversed by this treatment, we will measure the effect of IVIg on motor function using several techniques.

The primary outcome will be the impact of IVIg (placebo) on muscle strength as determined by serial quantitative isometric muscle strength measurements in the limbs affected by the 'targeted neurological deficit' (for example, monoparesis/plegia, paraparesis/plegia and hemiparesis/plegia). Specifically, the examining neurologist will indicate the targeted neurological deficit and corresponding isometric muscle strength testing sites at the enrollment visit. The test results at each site is the site specific strength, recorded as the percentage of normal (age and sex match controlled). These values will be averaged over the targeted sites for computation of the primary endpoint. We will then compute the difference between the six month and baseline value for each subject. Important secondary outcome measures will include an analysis of whether IVIg treatment (placebo) influences either dexterity and gait (serial videotaped examinations), spasticity (serial recordings of muscle tone; Ashworth spastity scale, ${ }^{48}{ }^{49}$ ) and function (Functional Independence Measure; Box and Blocks and 9 Hole Peg Tests). Although patients with tremor or truncal ataxia will not be excluded from enrollment, these functions will not be selected for study as the 'targeted neurological deficit'. All data will be used in these analyses, with patients analysed according to the treatment group to which they were randomised (intent to treat analysis).

This randomised, controlled trial has considerable practical relevance to MS. If improvement is seen, the time course of this change may provide insight into possible mechanisms of action of IVIg in MS and may suggest additional strategies which could be used to maximise the degree and rate of response. Additional studies will be necessary to determine whether similar improvements in other neurological functions will follow repeated IVIg administration (for example, cerebellar and sensory function, vision, bowel and bladder control, cognition, etc). Subsequent studies could be designed to determine whether IVIg administration is beneficial in the setting of either acute exacerbations (relapsing-remitting or relapsing-progressive disease) or chronic pro- gressive disease (primary or secondary progressive MS). This trial may provide the methodological framework to test other treatment approaches to promote CNS remyelination. The studies were supported by grants from the National
Multiple Sclerosis Society (RG2520-A1, RG 1878-B2 and RG 2174-A3), and the National Institutes of Health (RO1 2174-A3), and the National Institutes of Health (RO1 Pharmaceuticals Inc for providing the Gamimune $\mathrm{N}$ and phacebo preparations, Diane Sneve, Cathy Hunt and Jennifer Weis for their nursing expertise and Marian Bortolon for secretarial help.

1 Prineas JW, Connell F. Remyelination in multiple sclerosis. Ann Neurol 1979;5:22-31.

2 Raine CS, Scheinberg L, Waltz JM. Multiple sclerosis: Oligodendrocyte survival and proliferation in an active Oligodendrocyte survival and proliferation in

3 Prineas JW, Barnard RO, Kwon EE, Sharer LR, Cho E-S. Multiple sclerosis: Remyelination of nascent lesions. Ann Neurol 1993;33:137-51.

4 Prineas JW, Kwon EE, Goldenberg PZ, Kyas AA, Quarles RH, Benjamins JA, Sprinkle TJ. Multiple sclerosis: Oligodendrocytes proliferation and differentiation in fresh lesions. Lab Invest 1989;61:489-503.

5 Ghatak NR, Leshner RT, Price AC, Felton WL. Remyelination in the human central nervous system. f Neuropath Exp Neurol 1989;48:507-18.

6 Hirano A, Zimmerman HM, Levine S. Electron microscopic observations of peripheral myelin in a central nervous system lesion. Acta Neuropathol (Berl) 1969;12: vous -65 .

7 Itoyama Y, Webster HdeF, Richardson EP, Trapp BD. Schwann cell remyelination of demyelinated axons in the spinal cord multiple sclerosis lesions. Ann Neurol 1983; spinal cord

8 Rodriguez $M$, Oleszak E, Leibowitz J. Theiler's murine encephalomyelitis: A model of demyelination and persistence of virus. CRC Critical Reviews in Immunology 1987;7:325-66.

9 Lehrich JR, Arnason BG, Hochberg FH. Demyelinative myelopathy in mice induced by the DA virus. $₹$ Neurol Sci 1976;29:149-60.

$10 \mathrm{Dal}$ Canto MC, Lipton HL. Multiple sclerosis: animal model. Theiler's virus infection in mice. Am $\mathcal{f}$ Path 1977;88:497-500.

11 Dal Canto MC, Lipton HL. Recurrent demyelination in chronic central nervous system infection produced by Theiler's murine encephalomyelitis virus. $\mathcal{F}$ Neurol Sci 1979;42:391-405.

12 Rodriguez M, Siegel LM, Hovanec-Burns D, Bologa L, Graves MC. Theiler's virus-associated antigens on the surface of cultured glial cells. Virol 1988;166:463-74

13 Rodriguez M, Leibowitz JL, Lampert PW. Persistent infection of oligodendrocyte in Theiler's virus-induced encephalomyelitis. Ann Neurol 1983;13:426-33.

14 Roos RP, Wollmann R. DA strains of Theiler's murine encephalomyelitis virus induces demyelination in nude mice. Ann Neurol 1984;15:494-9.

15 Lipton HL, Dal Canto MC. Contrasting effects of immunosuppression on Theiler's virus infection in mice. immunosuppression on Theiler's

16 Rodriguez M, Quddus J. Effect of cyclosporin A, silica quartz dust and macrophage protease inhibitors on virus-induced demyelination. $f$ Neuroimmunol 1986; 13:159-174

17 Rodriguez M, Lafuse WP, Leibowitz J, David CS. Partial suppression of Theiler's virus-induced demyelination in vivo by administration of monoclonal antibodies to immune-response gene products (Ia antigens). Neurol 1986;30:964-70.

18 Friedman A, Frankel G, Lorch Y, Steinman L. Monoclonal anti-I-A antibody reverses chronic paralysis and demyelination in Theiler's virus-infected mice: Critical importance of timing of treatment. $\mathcal{F}$ Virol 1987;

19 Welsh CJR Tonks P, Nash AA, Blakemore WF. The effect of L3T4 T cell depletion on the pathogenesis of effect of L3T4 T cell depletion on the pathogenesis of Theiler's murine encephalomyelitis virus

20 Rodriguez M, Sriram S. Successful therapy of Theiler's virus-induced demyelination (DA strain) with monovirus-induced demyelination (DA strain) with mono-
clonal anti Lyt2 antibody. F Immunol 1988;140:2950-5.

21 Traugott U, Stone SH, Raine CS. Chronic relapsing experimental autoimmune encephalomyelitis treatment with combinations of myelin components promotes clinical and structural recovery. $\mathcal{F}$ Neurol Sci 1982;56:65-73.

22 Raine C, Traugott U. Chronic relapsing experimental autoimmune encephalomyelitis: Ultrastructure of the central nervous system of animals treated with combination of myelin components. Lab Invest 1983;48:275-84.

23 Raine CS, Hintzen $R$, Traugott $U$, Moore GRW. Oligodendrocyte proliferation and enhanced CNS 
remyelination after therapeutic manipulation of chronic relapsing EAE. Ann NY Acad Sci 1988;540:712-14.

24 Lang $\mathbb{W}$, Rodriguez $M$, Lennon VA, Lampert $P W$ Demyelination and remyelination in murine viral encephalomyelitis. Ann NY Acad Sci 1984;436:98-102.

25 Rodriguez M, Lennon V, Benveniste EN, Merrill JE. Remyelination by oligodendrocytes stimulated by antiserum to spinal cord. $f$ Neuropath Exp Neurol 1987; 46:84-95.

26 Rodriguez M, Lennon VA. Immunoglobulins promote remyelination in the central nervous system. Ann Neurol 1990;27:12-17.

27 Rodriguez $M$. Immunoglobulins stimulate central nervous system remyelination: electron microscopic and morsystem remyelination: electron microscopic and mor1991;64:358-70.

28 Rodriguez M, Scheithauer BW, Forbes T, Kelly PJ. Oligodendrocyte injury is an early event in lesions of multiple sclerosis. Mayo Clin Proc 1993;68:627-36.

29 Frohman LP, Cook SD, Bielory L. Dysgammaglobulinemia in steroid-dependent optic neuritis response to gammaglobulin treatment. $\mathcal{f}$ Clin Neuro Ophthalmol 1991;11(4):241-5.

30 van Engelen BGM, Hommes OR, Pinckers A, Cruysberg JRM, Barkhof F, Rodriguez M. Improved vision after intravenous immunoglobulin in stable demyelinating optic neuritis. Ann Neurol 1992;32:835-6.

31 Huizinga TW, van der Schoot CE, Jost C. The PI-linked receptor FcRIII is released on stimulation of neutrophils. receptor FcRIII is releas

32 Salama A, Mueller-Eckhardt C, Kiefel V. Effect of intravenous immunoglobulin in immune thrombocytopenia. Lancet 1984;2:193-5.

33 Hunziker W, Koch T, Whitney JA, Mellman I. Fc receptor phosphorylation during receptor-mediated control of Bcell activation. Nature 1990;345:628-32.

34 Dwyer JM. Intravenous therapy with gamma globulin. $A d v$ Intern Med 1987;32:111-35.

35 Engelhard D, Waner JL, Kapoor N, Good RA. Effect of intravenous immune globulin on natural killer cell activity: possible as and idiopathic thrombocytopenia. 7 Pediatr 1986;108: and idiop.

36 Sultan $Y$, Kazatchkine MD, Maisonneuve P, Nydegger UE. Anti-idiotypic suppression of autoantibodies to facto VIII by high-dose intravenous gamma globulin. Lancet 1984;2:765-8.
37 van Doorn PA, Rossi F, Brand A, van Lint M, Vermeulen $M$, Kazatchkine MD. On the mechanism of high-dose intravenous immunoglobulin treatment of patients with chronic inflammatory demyelinating polyneuropathy. chronic inflammatory demyelinat

38 Clark EA, Ledbetter JA. Amplification of the immune response by agonistic antibodies. Immunol Today 1986; 7:267-70.

39 Fukue Y, Uchimura H, Mitsuhasthi T, Okano S, Kanaji Y, Takaku F. Thyroglobulin release-stimulating activity in immunoglobulin $\mathrm{G}$ from patients with Graves' disease studied by human thyroid cells in vitro. 7 Clin Endo Metab 1987;64:261-5.

40 Dobi S, Lenkey B. Role of secretogogue immunoglobulins in gastric acid secretion. Acta Physio Acad Sci Hung 1982;60:9-25.

41 Ohta $Y$, Tamura $S$, Tezuka $E$ Sugawara $M$, Imai $S$, Tanaka $H$. Autoimmune MRL/LPR mice sera contain Tanaka $H$. Autoimmune MRU/LPR mice sera contain IgG with

42 Hirsch R, Gress RE, Pluznik DH, Eckhaus M, Bluestone JA. Effects of in vivo administration of anti CD3 monoclonal antibody on $\mathrm{T}$ cell function in mice. II. In vivo activition of T cells. F Immunol 1989;142:737-43.

43 Schumacher GA, Beebe GW, Kibler RF, et al. Problems of experimental trials of therapy in multiple sclerosis. Ann NY Acad Sci 1965;122:552-68.

44 Poser CM, Paty DW, Scheinberg L, et al. New diagnostic criteria for multiple sclerosis: Guidelines for research protocols. Ann Neurol 1983;13:227-31.

45 Kurtze JF, Beebe GW, Nagler B, Auth TL, Kurland LT, Nefzger MD. Studies on the natural history of multiple Nefzger $\mathrm{MD}$. Studies on the natural history of multiple sclerosis. 7. Correlates of clinical change in

46 Rault R, Piraino B, Johnston JR, Oral A. Pulmonary and renal toxicity of intravenous immunoglobulin. Clinical Nephrology 1991;36:83-6.

47 Tan E, Hajinazarian M, Bay W, Neff J, Mendell JR. Acute renal failure resulting from intravenous immunoglobulin therapy. Arch Neurol 1993;50:137-9.

48 Brar SP, Smith MB, Nelson LM, Franklin GM, Cobble ND. Evaluation of treatment protocols on minimal to moderate spasticity in multiple sclerosis. Arch Phys Med Rehabil 1991;72(3):186-9.

49 Penn RD. Intrathecal baclofen for spasticity of spinal origin: seven years of experience. $\mathcal{F}$ Neurosurg 1992;77(2): $236-40$. 